\title{
Cultura negra e educação
}

\section{Nilma Lino Gomes}

Universidade Federal de Minas Gerais, Faculdade de Educação
Denys Cuche (1999, p. 9), ao discutir a noção de cultura nas ciências sociais, destaca que o problema da cultura ou das culturas passa por um processo de atualização tanto no plano intelectual, quanto no plano político. O autor inicia essa discussão já na Introdução do seu livro, com uma epígrafe do antropólogo Marc Augé (1988). Nela, Marc Augé argumenta que, nos últimos anos, na França, a cultura tem sido bem mais destacada do que há tempos atrás. Segundo ele, esse uso da palavra cultura, por mais descontrolado que possa parecer, constitui por si mesmo um dado etnológico.

Guardadas as devidas proporções, podemos observar que um fato semelhante vem ocorrendo nos últimos anos no Brasil, e mais especificamente no campo da educação. Também entre nós, educadores e educadoras, nunca se falou tanto em cultura quanto hoje: cultura escolar, cultura da escola, diversidade cultural, multiculturalismo, interculturalismo, sujeitos socioculturais, cultura juvenil, cultura indígena, cultura negra...

Por mais que tal apelo à cultura possa significar um modismo pedagógico, ou o mais novo jargão da nossa área, ou uma mudança de paradigmas, acredito que só o fato da palavra cultura começar a fazer parte (ou voltar a fazer parte) do vocabulário educacional já constitui um dado pedagógico que merece nossa atenção. Constitui uma inflexão no pensamento educacional, fruto das mudanças ocorridas em nossa sociedade devido às ações e demandas dos movimentos sociais, dos grupos sociais e étnicos.

Mas se a ênfase na discussão da cultura no campo educacional se restringir ao simples elogio às diferenças ou ficar reduzida aos estudos do campo do currículo e da cultura escolar, corremos o risco de não explorar toda a riqueza que tal inflexão pode nos trazer.

A cultura, seja na educação ou nas ciências sociais, é mais do que um conceito acadêmico. Ela diz respeito às vivências concretas dos sujeitos, à variabilidade de formas de conceber o mundo, às particularidades e semelhanças construídas pelos seres humanos ao longo do processo histórico e social.

Os homens e as mulheres, por meio da cultura, estipulam regras, convencionam valores e significações que possibilitam a comunicação dos indivíduos e dos grupos. Por meio da cultura eles podem se adap- 
tar ao meio mas também o adaptam a si mesmos e, mais do que isso, podem transformá-lo. Segundo Rodrigues (1986, p. 11), a cultura é como um mapa que orienta o comportamento dos indivíduos em sua vida social. Esse mapa é puramente convencional, e por isso não se confunde com o território. Ele é uma representação abstrata do território, submetida a uma lógica que permite decifrá-lo. Dessa forma, ao refletirmos sobre o que é viver em sociedade e produzir cultura, entenderemos a complexidade dessa situação: significa que vivemos sob a dominação de uma lógica simbólica e que as pessoas se comportam segundo as exigências dela, muitas vezes sem que disso tenham consciência. Podemos então inferir que a vida coletiva, como a vida psíquica dos indivíduos, faz-se de representações, ou seja, das figurações mentais de seus componentes. Os sistemas de representação são construídos historicamente; eles originam-se do relacionamento dos indivíduos e dos grupos sociais e, ao mesmo tempo, regulam esse relacionamento. É a seguinte afirmação de José Carlos Rodrigues que se torna imprescindível para o campo educacional. Segundo ele, "o fato é que, uma vez constituídos, os sistemas de representações e sua lógica são introjetados pela educação nos indivíduos, de forma a fixar as similitudes essenciais que a vida coletiva supõe, garantindo, dessa maneira, para o sistema social, uma certa homogeneidade" (Rodrigues, 1986, p. 11).

Mas se as representações, as classificações, a reciprocidade e tantos outras aspectos da cultura podem ser considerados como grandes semelhanças, ou seja, os universais que nos identificam como humanos e sujeitos culturais, não podemos nos esquecer das particularidades. Guita Grin Debert (2000), ao estudar a especificidade da velhice em nossa sociedade, traz contribuições importantes para o debate sobre os universais e as particularidades. Ao tomar como objeto de estudo a especificidade da velhice enquanto um grupo de idade, Debert nos alerta para tomarmos cuidado com a ênfase nos universais, pois na tentativa de encontrar o que é comum em experiências culturais diferentes, multifacetadas e fragmentadas, eles acabam transformando-se em "categorias vazias". Debert recorre ao antropólogo Clifford Geertz (1978, p. 52) para fundamentar a sua crítica:

O fato de que em todos os lugares as pessoas se juntam e procriam filhos, têm algum sentido do que é meu e do que é teu, e se protegem, de alguma forma, contra a chuva e o sol não é nem falso nem sem importância, sob alguns pontos de vista. Todavia, isso pouco ajuda no traçar um retrato do homem que seja uma presença verdadeira e honesta e não uma espécie de caricatura de um "João universal", sem crenças e credos.

Essa crítica ao pressuposto de que a essência do ser humano se revela nos aspectos que são universais às culturas deve ser considerada pela educação. De acordo com Geertz, "pode ser que nas particularidades culturais dos povos - em suas esquisitices - sejam encontradas algumas das revelações mais instrutivas sobre o que é ser genericamente humano" (1978, p. 55). Sendo assim, o que nos faz mais semelhantes ou mais humanos são as diferenças.

E é com esse olhar que penso a relação entre cultura negra e educação. Parto da concordância de que negros e brancos são iguais do ponto de vista genético, porém discuto que, ao longo da experiência histórica, social e cultural, a diferença entre ambos foi construída, pela cultura, como uma forma de classificação do humano. No entanto, no contexto das relações de poder e dominação, essas diferenças foram transformadas em formas de hierarquizar indivíduos, grupos e povos. As propriedades biológicas foram capturadas pela cultura e por ela transformadas. Esse processo, que também acontece com o sexo e a idade, apresenta variações de uma sociedade para outra.

No caso do negro brasileiro, a classificação e a hierarquização racial hoje existentes, construídas na efervescência das relações sociais e no contexto da escravidão e do racismo, passaram a regular as relações entre negros e brancos como mais uma lógica desenvolvida no interior da nossa sociedade. Uma vez constituídas, são introjetadas nos indivíduos negros e brancos pela cultura. Somos educados pelo meio sociocultural a enxergar certas diferenças, as quais fa- 
zem parte de um sistema de representações construído socialmente por meio de tensões, conflitos, acordos e negociações sociais.

A escola, enquanto instituição social responsável pela organização, transmissão e socialização do conhecimento e da cultura, revela-se como um dos espaços em que as representações negativas sobre o negro são difundidas. E por isso mesmo ela também é um importante local onde estas podem ser superadas.

Cabe ao educador e à educadora compreender como os diferentes povos, ao longo da história, classificaram a si mesmos e aos outros, como certas classificações foram hierarquizadas no contexto do racismo e como este fenômeno interfere na construção da auto-estima e impede a construção de uma escola democrática. É também tarefa do educador e da educadora entender o conjunto de representações sobre o negro existente na sociedade e na escola, e enfatizar as representações positivas construídas politicamente pelos movimentos negros e pela comunidade negra. A discussão sobre a cultura negra poderá nos ajudar nessa tarefa.

Mas isso requer um posicionamento. Implica a construção de práticas pedagógicas de combate à discriminação racial, um rompimento com a "naturalização" das diferenças étnico/raciais, pois esta sempre desliza para o racismo biológico e acaba por reforçar o mito da democracia racial. Uma alternativa para a construção de práticas pedagógicas que se posicionem contra a discriminação racial é a compreensão, a divulgação e o trabalho educativo que destaca a radicalidade da cultura negra. Essa é uma tarefa tanto dos cursos de formação de professores quanto dos profissionais e pesquisadores/as que já estão na prática.

A cultura negra pode ser vista como uma particularidade cultural construída historicamente por um grupo étnico/racial específico, não de maneira isolada, mas no contato com outros grupos e povos. Essa cultura faz-se presente no modo de vida do brasileiro, seja qual for o seu pertencimento étnico. Todavia, a sua predominância se dá entre os descendentes de africanos escravizados no Brasil, ou seja, o segmento negro da população.
No caso específico da educação escolar, ao tentarmos compreender, debater e problematizar a cultura negra, não podemos desconsiderar a existência do racismo e da desigualdade entre negros e brancos em nossa sociedade. Por quê? Porque ao fazermos tal ponderação inevitavelmente nos afastaremos das práticas educativas que, ao tentarem destacar essa cultura no interior da escola ou no discurso pedagógico, ainda a colocam no lugar do exótico e do folclore.

Discutir sobre a cultura negra também exigirá de nós um posicionamento sobre o que realmente queremos dizer quando apelamos para a construção de projetos e práticas multiculturais (tão em moda ultimamente) e nos direcionará a um compromisso político explícito diante da questão racial, entendida aqui como indissoluvelmente ligada ao conjunto de questões sociais, culturais, históricas e políticas do nosso país. Isso nos leva a pensar nas ações afirmativas para o povo negro e à forma como os educadores e as educadoras, negros e brancos, favoráveis à discussão e à inserção da cultura negra no currículo escolar, posicionam-se diante delas.

Por tudo isso, reitero que tratar, trabalhar, lidar, problematizar e discutir sobre educação e cultura negra no Brasil é assumir uma postura política. De forma alguma as relações culturais e sociais entre negros e brancos em nosso país podem ser pensadas como harmoniosas, democráticas e diluídas nas questões socioeconômicas. Os últimos dados do Instituto Brasileiro de Geografia e Estatística - IBGE - e do Instituto de Pesquisa Econômica Aplicada - IPEA sobre as desigualdades raciais deveriam ser fonte de consulta para os pesquisadores e pesquisadoras da educação que se interessam pelo tema.

\section{Cultura negra e práticas pedagógicas}

Hoje já está comprovado pela biologia e pela genética que todos os seres humanos possuem a mesma carga genética. Tais estudos são importantes para desconstruir e superar as teorias racistas que predominaram na intelectualidade no final do século XIX e 
início do século XX, e cujo teor, infelizmente, ainda se faz presente na sociedade brasileira.

Mas se todos partilhamos de semelhanças como seres humanos, o que nos faz diferentes? Segundo Denys Cuche (1999, p. 10), são as nossas escolhas, a forma como cada grupo cultural inventa soluções originais para os problemas que lhes são colocados pela vida em sociedade e ao longo do processo histórico. Essas escolhas não são simplesmente mecânicas e empíricas. Elas não estão relacionadas somente à adaptação ao meio, mas às disputas de poder entre grupos e povos. Nessas disputas as diferenças são inventadas, e através delas nos aproximamos de uns e tornamos outros inimigos, adversários, inferiores ou "violentos".

Nesse sentido, podemos compreender que as diferenças, mesmo aquelas que nos apresentam como as mais físicas, biológicas e visíveis a olho nu, são construídas, inventadas pela cultura. A natureza é interpretada pela cultura. Ao pensarmos dessa forma, entramos nos domínios do simbólico. É nesse campo que foram construídas as diferenças étnico/raciais.

Apelar para a existência da "raça" do ponto de vista da genética é, atualmente, cair na cilada do racismo biológico. Todos concordamos que "raça" é um conceito cientificamente inoperante. Porém, social e politicamente, ele é um conceito relevante para pensar os lugares ocupados e a situação dos negros e brancos em nossa sociedade. Quando o movimento negro e pesquisadores da questão racial discutem sobre a raça negra, hoje, estão usando esse conceito do ponto de vista político e social, com toda uma ressignificação que o mesmo recebeu dos próprios negros ao longo da nossa história. Por isso, a discussão sobre raça, racismo e cultura negra nas ciências sociais e na escola é uma discussão política. Ao não politizarmos a "raça" e a cultura negra caímos fatalmente nas malhas do racismo e do mito da democracia racial.

Essa politização da raça e da cultura negra não implica a entrada para o movimento social negro, o que não deixa de ser uma boa experiência. Significa saber que estamos entrando em um terreno complexo, em que identidades foram fragmentadas, auto-estimas podem estar sendo destruídas. A fome, a pobreza e a desigualdade têm incidido com mais contundência sobre os descentes de africanos em nosso país do que em relação ao segmento branco. Como dizem alguns pesquisadores: elas têm cor. A reversão desse quadro diz respeito à construção de políticas públicas específicas, tanto na educação básica quanto no ensino superior. Significa resgatar a positividade dessa cultura, a sua beleza, a sua radicalidade e sua presença na constituição da nossa formação cultural.

Refletir sobre a cultura negra é considerar as lógicas simbólicas construídas ao longo da história por um grupo sociocultural específico: os descendentes de africanos escravizados no Brasil. Se partirmos do pressuposto de que o nosso país, hoje, é uma nação miscigenada, diríamos que a maioria da sociedade brasileira se encaixa nesse perfil, ou seja, uma grande parte dos brasileiros pode se considerar descendente de africanos. Porém, refiro-me aqui ao grupo étnico/ racial classificado socialmente como negro.

Embora alguns antropólogos tratem com desconfiança a adjetivação de uma cultura como "negra", o que importa aqui é destacar que a produção cultural oriunda dos africanos escravizados no Brasil e ainda presente nos seus descendentes tem uma efetividade na construção identitária dos sujeitos socialmente classificados como negros. Não se trata de cairmos no racismo biológico, nem de afirmarmos que o fenótipo é o único determinante da posição ocupada pelas pessoas na sociedade brasileira. Trata-se de compreender que há uma lógica gerada no bojo de uma africanidade recriada no Brasil, a qual impregna a vida de todos nós, negros e brancos. E isso não tem nada de natural. Essa inexistência de algo puramente natural na sociedade pode ser vista inclusive quando ponderamos sobre a existência das teorias racistas. Embora elas apregoassem trabalhar somente com os dados biológicos para atestarem a suposta inferioridade do negro, na realidade elas operavam e ainda operam o tempo todo no campo da cultura. Nesse sentido, qualquer adjetivação da cultura, seja cigana, judaica, indígena ou negra, é uma construção social, política, ideológica e cultural que, numa sociedade que tende 
a discriminar e tratar desigualmente as diferenças, passa a ter uma validade política e identitária.

A cultura negra possibilita aos negros a construção de um "nós", de uma história e de uma identidade. Diz respeito à consciência cultural, à estética, à corporeidade, à musicalidade, à religiosidade, à vivência da negritude, marcadas por um processo de africanidade e recriação cultural. Esse "nós" possibilita o posicionamento de negro diante do outro e destaca aspectos relevantes da sua história e de sua ancestralidade.

A cultura negra só pode ser entendida na relação com as outras culturas existentes em nosso país. E nessa relação não há nenhuma pureza; antes, existe um processo contínuo de troca bilateral, de mudança, de criação e recriação, de significação e ressignificação. Quando a escola desconsidera esses aspectos ela tende a essencializar a cultura negra e, por conseguinte, a submete a um processo de cristalização ou de folclorização.

François Neyt e Catherine Vanderhaeghe (2000) perguntam: "Quantos séculos serão necessários para avaliarmos a riqueza e a fecundidade das tradições culturais africanas? Elas retornam em ondas musicais e artísticas, sob formas sempre novas e diferentes, fiéis à sua inspiração primordial” (p. 34).

Parafraseando os autores, poderíamos perguntar: Quanto tempo ainda esperaremos para que a escola e os educadores/as avaliem de forma séria e não essencializada a riqueza e a fecundidade da cultura negra construída no Brasil, e o seu peso na formação cultural das outras etnias?

A construção de uma prática pedagógica que se configure como uma resposta a essa pergunta não se limita à produção de pesquisas sobre o tema, nem ao documento "pluralidade cultural" dos Parâmetros Curriculares Nacionais. Na minha opinião, trabalhar com a cultura negra, na educação de um modo geral e na escola em específico, é considerar a consciência cultural do povo negro, ou seja, é atentar para o uso auto-reflexivo dessa cultura pelos sujeitos. Significa compreender como as crianças, adolescentes, jovens, adultos e velhos negros e negras constroem, vivem e reinventam suas tradições culturais de matriz africa- na na vida cotidiana. Um professor ou professora, ou mesmo um pesquisador ou pesquisadora que estiver alerta para essa realidade perceberá o quanto a herança ancestral africana recriada no Brasil - e que nesse artigo chamamos de cultura negra - orienta e traz inspiração para os negros da diáspora. Sempre sob formas diferentes, essa herança está entre nós (e em nós) e se objetiva na história, nos costumes, nas ondas musicais, nas crenças, nas narrativas, nas histórias contadas pelas mães e pais/griôts, nas lendas, nos mitos, nos saberes acumulados, na medicina, na arte afrobrasileira, na estética, no corpo. Muito desse processo acontece de forma inconsciente. Tomemos, então, dois aspectos que merecem ser destacados e observados pelos educadores(as) ao discutirem sobre a cultura negra no Brasil: o corpo como expressão da identidade negra e a manipulação do cabelo.

\section{0 corpo como expressão da identidade negra}

O corpo pode simbolizar diferentes identidades sociais, extrapolando a dimensão do indivíduo e da pessoa. De acordo com José Carlos Rodrigues (1986, p. 45), o corpo é sempre uma representação da sociedade, por isso não há processo exclusivamente biológico no comportamento humano.

Nenhum outro animal transforma voluntariamente o próprio corpo. Essa é uma característica dos seres humanos. As transformações que os homens imprimem ao corpo, além de variarem de acordo com cada cultura, também acontecem conforme a especificidade dos segmentos sociais no interior de um mesmo grupo. Por isso a forma de manipular o corpo, os sinais nele impressos e o tipo de penteado podem significar hierarquia, idade, símbolo de status, de poder e de realeza entre sujeitos de um mesmo grupo cultural ou entre diferentes grupos.

Segundo Rodrigues (1986, p. 159), o corpo expressa metaforicamente os princípios estruturais da vida coletiva. Há no organismo forças controladas e forças que ignoram o controle social e o ameaçam. Assim, o corpo pode simbolizar aquilo que uma sociedade deseja ser, assim como o que se deseja negar. 
Uma sociedade racista usa de várias estratégias para discriminar o negro. Alguns aspectos corporais, no contexto do racismo, são tomados pela cultura e recebem um tratamento discriminatório. São estratégias para retirar do negro o status de humanidade. Talvez seja esta uma das piores maneiras de o racismo se perpetuar. Ele transforma as diferenças inscritas no corpo em marcas de inferioridade. Nesse processo são estabelecidos padrões de superioridade/ inferioridade, beleza/feiúra.

O cabelo crespo é um dos argumentos usados para retirar o negro do lugar da beleza. $\mathrm{O}$ fato de a sociedade brasileira insistir tanto em negar aos negros e às negras o direito de serem vistos como belos expressa, na realidade, o quanto esse grupo e sua expressão estética possuem um lugar de destaque na nossa constituição histórica e cultural. O negro é o ponto de referência para a construção da alteridade em nossa sociedade. Ele é o ponto de referência para a construção da identidade do branco. Juntamente com o índio, o negro concretiza a nossa sociedade, a nossa cultura, as nossas relações sociais, políticas e econômicas. Como afirma Rodrigues (1999, p. 26), “aquilo que não quero ser é parte 'inabstraível' do que sou, aquilo que uma sociedade renega é intimamente integrante de si".

Enquanto imagem social, o corpo é a representação exterior do que somos. É o que nos coloca em contato com o mundo externo, com o "outro", por isso ele carrega em si a idéia de relação. Sabendo que a identidade negra em nossa sociedade se constrói imersa no movimento de rejeição/aceitação do ser negro, é compreensível que os diferentes sentidos atribuídos pelo homem e pela mulher negra ao seu cabelo e ao seu corpo revelem uma maneira tensa e conflituosa de "lidar" com a corporeidade enquanto uma dimensão exterior e interior da negritude.

O corpo apresenta a dupla capacidade de ser, ao mesmo tempo, objeto e sujeito da natureza e da cultura. Essa dupla capacidade é trabalhada pioneiramente na antropologia por Marcel Mauss (1974), no ensaio intitulado "As técnicas corporais". O autor afirma que não se pode negar que o corpo humano constitui uma entidade biológica, sendo o mais natural e o primeiro instrumento do homem. Por isso ele encontrase submetido a algumas imposições elementares da natureza, colocando a todos nós em uma mesma e única condição. Em contrapartida, é preciso considerar que o corpo é objeto de alteração exercida pela cultura, sendo por ela modelado e modificado. Temos então, expressos no corpo, os universais e as particularidades da cultura.

Embora possa não parecer, em cada cultura há regras especiais para tossir, cuspir e espirrar, fazer a higiene corporal, cuidar da estética corporal, praticar esportes, lazer, entre outros. A cultura também determina as posições a serem adotadas para agachar, ficar de pé, descansar, sentar e as formas consideradas corretas para utilizar os instrumentos mais diversos, desde aqueles que são utilizados para alimentação até os usados no trabalho. Todas essas posturas e posições são aprendidas socialmente.

Marcel Mauss revela como as forças sociais convergem no corpo. $\mathrm{O}$ autor procura compreender as formas pelas quais os seres humanos, em cada cultura, nas diferentes sociedades, usam seus corpos. Partindo da evidência de que cada formação social tem os hábitos que são próprios, Mauss descreveu, e de certo modo inventariou, uma enorme variedade de "técnicas corporais", ou seja, de "atos montados, e montados no indivíduo não simplesmente por ele mesmo, mas por toda a sua educação, por toda a sociedade da qual ele faz parte, no lugar que ele nela ocupa" (Mauss, 1974, p. 218).

Em cada uma dessas técnicas está presente uma confluência de forças sociais, em relação às quais a base física do corpo não é senão a matéria sobre a qual essa convergência se aplica. Mauss percebe que o social se faz presente nas menores ações humanas. Nas diferentes culturas, as práticas que, a princípio, podem parecer insignificantes, traduzem mensagens, normalmente inconscientes, sobre o que é certo e o que é errado, o que é considerado "coisa dos homens" e o que é "coisa dos bichos", o que é igual e o que é diferente, o que é respeitoso e o que é profanação, o que é nobre e o que é indigno, o que é considerado 
feio e o que é bonito, entre outros. O efeito conotativo de tais práticas vai muito além do que se poderia esperar do seu fraco poder denotativo (Rodrigues, 1986, p. 96-97).

Mas um fato relevante destaca-se nas considerações de Marcel Mauss. Segundo ele, as técnicas corporais são transmitidas por meio da educação. Elas são atos tradicionais e eficazes, e, segundo o autor, "é nisso que o homem se distingue sobretudo dos animais: pela transmissão de suas técnicas e muito provavelmente por sua transmissão oral" (Mauss, 1974, p. 217). Assim, a educação é o meio através do qual o homem aprende a trabalhar o corpo, transmitindo de geração em geração as técnicas, a arte e os meios dessa manipulação. Tudo isso ela faz através da linguagem. Por isso podemos pensar que cada sociedade desenvolve a sua pedagogia corporal. Esse processo é mais do que imitação pura e simples. Ele é cultural.

A educação pode desenvolver uma pedagogia corporal que destaque a riqueza da cultura negra inscrita no corpo, nas técnicas corporais, nos estilos de penteados e nas vestimentas, as quais também são transmitidas oralmente. São aprendizados da infância e da adolescência. O corpo negro pode ser tomado como símbolo de beleza, e não de inferioridade. Ele pode ser visto como o corpo guerreiro, belo, atuante presente na história do negro da diáspora, e não como o corpo do escravo, servil, doente e acorrentado como lamentavelmente nos é apresentado em muitos manuais didáticos do ensino fundamental.

O cabelo é um dos elementos mais visíveis e destacados do corpo. Em todo e qualquer grupo étnico ele apresenta características como visibilidade, crescimento, diferentes cores e texturas, possibilitando técnicas diversas de manipulação sem necessariamente estar subordinado ao uso de tecnologias sofisticadas. Ao mesmo tempo, a forma como o cabelo é tratado e manipulado, assim como a sua simbologia, diferem de cultura para cultura. Esse caráter universal e particular do cabelo atesta a sua importância como ícone identitário.

Se concordamos que o corpo carrega muitas e diferentes mensagens, podemos concluir também que o entendimento da simbologia do corpo negro e os sentidos da manipulação de suas diferentes partes, entre elas o cabelo, pode ser um dos caminhos para a compreensão da cultura negra em nossa sociedade.

No processo histórico e cultural brasileiro, o negro, sobretudo as mulheres negras, constrói sua corporeidade por meio de um aprendizado que incorpora um movimento tenso de rejeição/aceitação, negação/ afirmação do corpo. Porém, não basta apenas para o negro brasileiro avançar do pólo da rejeição para o da aceitação para que compreenda e valorize a riqueza da sua cultura. Ver-se e aceitar-se negro toca em questões identitárias complexas. Implica, sobretudo, a ressignificação de um pertencimento étnico/racial no plano individual e coletivo.

Falar em corpo nos remete, inevitavelmente, aos padrões de beleza. É fato que cada grupo cultural define a beleza à sua própria maneira, e que "o belo é subjetivo e se fixa no olho do contemplador" (Munanga, 1988, p. 7). Porém, é também verdade que esta autonomia é parcial, uma vez que a beleza ainda está submetida a padrões etnocêntricos - que se pretendem universais -, os quais primam pelo equilíbrio de formas e de proporcionalidade. Para além do princípio universal de apreensão do mundo, de conhecimento do objeto mediante os sentidos, temos presenciado no decorrer do processo histórico que a partir do século XV construiu-se um padrão hegemônico de beleza e proporcionalidade baseados na Europa colonial. A partir de então, quando aplicamos o conceito de beleza aos corpos, passamos por um processo muitas vezes rígido de classificação e hierarquização, e a aparência física passa a carregar significados ligados a atributos negativos ou positivos. Esse ideal de beleza, visto por alguns como universal é, na realidade, construído socialmente, num contexto histórico, cultural e político, e por isso mesmo pode ser ressignificado pelos sujeitos sociais. Esse é o papel da discussão sobre cultura negra na educação: ressignificar e construir representações positivas sobre o negro, sua história, sua cultura, sua corporeidade e sua estética. 


\section{A manipulação do cabelo como uma dimensão da cultura negra}

Por mais que a escravidão e a diáspora negra tenham obtido algum sucesso na despersonalização do negro, por mais que a mistura racial tenha mesclado corpos, costumes e tradições, e por mais que o contato com o branco colonizador tenha disseminado um processo de discriminação intra-racial entre os negros e introduzido uma hierarquização racial que elege o tipo de cabelo e a cor da pele como símbolos de beleza ou de feiúra, todo esse processo não conseguiu apagar as marcas simbólicas e objetivas que nos remetem à ascendência africana. Os corpos e a manipulação do cabelo são depósitos da memória.

A escritora Ayana D. Byrd e a jornalista Lori L. Tharps (2001) registram que no início do século XV o cabelo funcionava como um condutor de mensagens na maioria das sociedades africanas ocidentais. Muitos integrantes dessas sociedades, incluindo os Wolof, Mende, Mandingo e Iorubás, foram escravizados e trazidos para o Novo Mundo. Nessas culturas o cabelo era parte integrante de um complexo sistema de linguagem. Desde o surgimento da civilização africana, o estilo do cabelo tem sido usado para indicar o estado civil, a origem geográfica, a idade, a religião, a identidade étnica, a riqueza e a posição social das pessoas. Em algumas culturas, o sobrenome de uma pessoa podia ser descoberto simplesmente pelo exame do cabelo, pois cada clã tinha o seu próprio e único estilo.

O significado social do cabelo era uma riqueza para o africano. Dessa forma, os aspectos estéticos assumiam um lugar de importância na vida cultural das diferentes etnias. Várias comunidades da África Ocidental admiravam a mulher de cabeça delicada com cabelos anelados e grossos. Esse padrão estético demonstrava força, poder de multiplicação, prosperidade e a possibilidade de parir crianças saudáveis.

Byrd e Tharps (2001, p. 4), na sua reconstrução histórica sobre os significados culturais do cabelo construídos pelos africanos e pelos negros da diáspora, citam uma interessante pesquisa da antropóloga Sylvia A. Boone, especialista no estudo da cultura Mende de Serra Leoa. De acordo com essa antropóloga, uma cabeça grande e com muito cabelo eram qualidades que as mulheres africanas queriam ter. Mas era preciso mais do que uma quantidade abundante de cabelo para ser bonita. Ele deveria ser limpo, asseado e penteado com um determinado estilo, geralmente um desenho específico de trança, conforme a tradição de cada grupo étnico.

Um estilo particular de cabelo poderia ser usado para atrair a pessoa do sexo oposto ou como sinal de um ritual religioso. Na Nigéria, se uma mulher deixava o cabelo despenteado era sinal de que alguma coisa estava errada: a mulher estava de luto, deprimida ou suja. Para os Mende, um cabelo despenteado, desleixado ou sujo implicava que a mulher tinha "perdido" a moral ou era insana.

A interpretação e a descrição etnográfica da antropóloga Sylvia A. Boone também se aplicam às mulheres senegalesas. Segundo ela, as mulheres Wolof gostam de manter seus cabelos lustrosos e longos. Ele não era cortado, mas artesanalmente penteado. Um cabelo despenteado era freqüentemente interpretado como um sinal de demência. Os homens também se enquadravam em tais padrões estéticos. Deles era sempre esperado que mantivessem seus locks limpos e arrumados, usados em estilo mais simples ou com uma criação mais elaborada.

A força simbólica do cabelo para os africanos continua de maneira recriada e ressignificada entre nós, seus descendentes. Ela pode ser vista nas práticas cotidianas e nas intervenções estéticas desenvolvidas pelas cabeleireiras e cabeleireiros étnicos, pelas trançadeiras em domicílio, pela família negra que corta e penteia o cabelo da menina e do menino. Pode ser vista também nas tranças, nos dreads e penteados usados pela juventude negra e branca. Se no processo da escravidão o negro não encontrava no seu cotidiano um lugar, quer fosse público ou privado, para celebrar o cabelo como se fazia na África, no mundo contemporâneo alguns espaços foram construídos para atender a essa prática cultural. Os salões étnicos es- 
palhados pelas mais diferentes cidades e estados brasileiros apresentam-se como um dos espaços em que essa celebração é possível. Será que ela também é possível na escola?

Para entender esse processo de recriação da memória, que afeta a maneira como a beleza é vista e construída pelos negros, o estudo dos penteados e do simbolismo do cabelo torna-se uma necessidade e uma condição. Este é um campo de pesquisa pouco explorado no Brasil. A diferenciação na confecção dos diferentes tipos de penteados mostra-nos um processo de evolução plástica quando comparamos as técnicas tradicionais de manipular o cabelo com a moderna tecnologia. Este é um estudo interessante, que envolve história, geografia, estética e cultura negra, e que pode ser desenvolvido pelos educadores. Recolher as práticas culturais ligadas aos penteados pode ser uma instigante tarefa para os adolescentes e jovens negros e brancos das nossas escolas.

Apesar da ruptura na estrutura social causada pela transplantação dos africanos para o Novo Mundo, pelo processo de despersonalização e de fragmentação da identidade, as formas de recriação cultural através da manipulação do cabelo - que podem ser vistas no interior da escola, nos bairros populares, nos bailes funks, no movimento hip-hop, nos grupos de dançaafro -, continuam impregnadas de africanidade. Podemos dizer, então, que a manipulação do cabelo do negro não nos fala apenas da modernidade, das técnicas modernas de alisamento e relaxamento, da estilização de penteados, da reprodução da ideologia do branqueamento e do mito da democracia racial, mas também de processos de resistência. Como diz Kabengele Munanga:

Para que os elementos culturais africanos pudessem sobreviver à condição de despersonalização de seus portadores pela escravidão, eles deveriam ter, a priori, valores mais profundos. A esses valores primários, vistos como continuidade, foram acrescidos novos valores que emergiram do novo ambiente. (2000, p. 99)

Hoje, mais do que nunca, estamos diante de di- ferentes lógicas de estilização negra. $\mathrm{O}$ processo de continuidade e recriação de elementos da cultura africana no Brasil sofre influências não só devido à experiência da diáspora, mas ao contexto histórico, às mudanças econômicas, à globalização, à exclusão social, às transformações no mundo da moda e às atuais condições de vida da população. Porém, mesmo que de uma forma parcial, os negros, através das suas técnicas corporais, guardam como evidência de uma tradição africana o lugar ocupado pelo cabelo na estruturação da sua vida social e psíquica.

Assim, não é só por mera vaidade ou por não se sentirem satisfeitos com a sua aparência que os negros e as negras dão tanta atenção ao cabelo. Para o homem e a mulher negra, manipular o cabelo representa uma dentre as múltiplas formas de expressão da corporeidade e da cultura, as quais remetem a uma raiz ancestral. Nesse sentido, os penteados utilizados pelos negros da diáspora e suas técnicas complexas mantêm uma certa inspiração africana, mesmo que esta não esteja no plano da consciência.

A presença da cultura negra no Brasil, na qual insiro os penteados e a manipulação do cabelo, pode ser vista dentro de um movimento de circularidade cultural. O fato de haver uma circulação desses elementos da África para o Novo Mundo, e dele retornando e influenciando, inclusive, a moda e o estilo dos africanos contemporâneos, reforça a minha hipótese da profunda capacidade de enraizamento da matriz africana na construção da cultura negra em nosso país. Reitero que não há, no Brasil, nenhuma cópia ou reprodução literal da cultura de matriz africana, mas sua recriação a partir da construção histórica e social do negro da diáspora.

Dessa forma, insisto que não seria ousado acrescentar que, ao lado da religiosidade, vista como um campo cultural muito resistente, no qual se pôde nitidamente observar o fenômeno de continuidade de elementos culturais africanos, encontramos também, no Brasil, a manipulação do cabelo através dos cortes, tranças, penteados e diferentes estilos, e que esta pode ser considerada um dos aspectos da cultura negra em nosso país. 


\section{Considerações finais}

Muitos aspectos da cultura negra presentes no Brasil poderiam ainda ser destacados. Elegemos, neste artigo, a corporeidade e a manipulação do cabelo para exemplificar a riqueza dessa cultura e sua forte presença entre nós. São aspectos que, a princípio, parecem não manter nenhuma relação com a educação. Mas, se retomarmos alguns pontos destacados no início deste artigo, veremos que o educativo é eminentemente cultural e que a relação ensino/aprendizagem se constrói no campo dos valores, das representações e de diferentes lógicas. Não lidamos somente com processos cognitivos. Aliás, cada vez mais descobrimos que a cognição é construída na cultura. Dessa forma, a pesquisa educacional sempre será enriquecida pelo diálogo com outras áreas das ciências humanas. No caso do estudo sobre a questão racial, é importante que esse diálogo se dê com as áreas do conhecimento que, pela sua história, possuem um acúmulo na discussão sobre a cultura e, no caso específico deste artigo, a cultura negra.

Como já foi dito também, ao se discutir sobre a cultura negra não podemos nos esquecer de denunciar a lamentável existência do racismo entre nós. A ausência dessa discussão nas pesquisas educacionais que se propõem a investigar as relações raciais e a formação cultural negra na educação brasileira pode nos conduzir a um debate despolitizado sobre o tema.

Porém, não podemos restringir o debate e a pesquisa sobre o negro e sua cultura somente aos efeitos nefastos do racismo. Perceber as lógicas por meio das quais os negros e negras expressam seus sentimentos e atribuem sentido ao mundo, destacar aspectos pouco explorados da cultura negra, resgatar a história da África e da sua cultura e as semelhanças existentes entre esse continente e a sociedade brasileira é também uma tarefa necessária para o campo da pesquisa educacional.

Cada vez mais confirmaremos que, para entender o Brasil, é preciso conhecer e compreender a África. E ao aceitarmos esse desafio fatalmente teremos que nos posicionar diante das condições reais vividas hoje por vários países africanos, fruto de um processo truculento de colonização e exploração. Em tempos de globalização, em que denúncias sobre a globalização da miséria têm sido feitas incessantemente, não há como continuarmos considerando a África como matriz estética de vários movimentos da arte e da cultura contemporâneos e, ao mesmo tempo, ignorarmos o drama de exclusão e miséria imposto ao povo africano.

NILMA LINO GOMES, doutora em Antropologia Social pela USP, é professora do Departamento de Administração Escolar da Faculdade de Educação da UFMG e coordenadora do Projeto Ações Afirmativas na UFMG, aprovado pelo concurso Cor no Ensino Superior do Programa Políticas da Cor, do Laboratório de Políticas Públicas da UERJ. Algumas publicações: "Iguales y diferentes: escuela y diversidad cultural” In: Pablo Gentili (coord.) Códigos para la ciudadanía: la formacíon ética como prática de la libertad (Buenos Aires: Santillana, 2000), "Educação cidadã, etnia e raça: o trato pedagógico da diversidade". In: Eliane Cavalleiro (org.) Racismo e anti-racismo na educação; repensando nossa escola (São Paulo: Selo Negro, 2001), "O desafio da diversidade" In: Nilma Lino Gomes e Petronilha Beatriz e Gonçalves e Silva (orgs.). Experiências étnico-culturais para a formação de professores (Belo Horizonte: Autêntica, 2002). Organizou em parceria com Lilia K. M. Schwarcz: Antropologia e história: debate em região de fronteira (Belo Horizonte: Autêntica, 2000) e com Petronilha Beatriz Gonçalves e Silva: Experiências étnico/culturais para a formação de professores (Belo Horizonte: Autêntica, 2002). Desenvolve atualmente a pesquisa: Práticas culturais, juventude e identidade negra. E-mail: nilmagomes@uol.com.br

\section{Referências bibliográficas}

AUGÉ, Marc, (1988). L'autre proche. In : SEGALEN, Martine (ed.). L'autre et le semblable: regards sur l'ethnologie des sociétés contemporaines. Paris: Presses du CNRS. p. 19-34.

BYRD, Ayana D., THARPS, Lori L., (2001). Hair story : untangling the roots of black hair in America. New York: St. Martin's Press.

CUCHE, Denys, (1999). A noção de cultura nas ciências sociais. Bauru: Edusc. Tradução de Viviane Ribeiro.

DEBERT, Guita Grin, (2000). A antropologia e o estudo dos grupos e categorias de idade. In: MORAES, Myriam, BARROS, 
Lins de (orgs.). Velhice ou terceira idade? Rio de Janeiro: Editora FGV. p. 49-67.

GEERTZ, Clifford, (1978). A interpretação das culturas. Rio de Janeiro: Zahar.

GOMES, Nilma Lino, (2002). Corpo e cabelo como ícones de construção da beleza e da identidade negra nos salões étnicos de Belo Horizonte. Tese de doutorado em Antropologia Social. Faculdade de Filosofia, Letras e Ciências Humanas da Universidade de São Paulo.

MAUSS, Marcel, (1974). As técnicas corporais. In: Sociologia e antropologia. São Paulo: EPU. p. 209-233.

MUNANGA, Kabengele, (1988). A criação artística negro-africana: uma arte situada na fronteira entre a contemplação e a utilidade prática. África Negra. Salvador: Prefeitura Municipal de Salvador/Fundação Gregório de Mattos/Museu de Arte de São Paulo Assis Chateaubriand, 11 de maio a 26 de junho. p. 7-9. (2000). Arte afro-brasileira: o que é, afinal? In: Mostra do redescobrimento: arte afro-brasileira. Associação
500 anos Brasil artes visuais. São Paulo: Fundação Bienal de São Paulo. p. 98-111.

NEYT, François, VANDERHAEGHE, Catherine, (2000). A arte das cortes da África negra no Brasil. In: Mostra do redescobrimento: arte afro-brasileira. Associação 500 anos Brasil artes visuais. São Paulo: Fundação Bienal de São Paulo. p. 34-97.

RODRIGUES, José Carlos, (1986). O tabu do corpo. Rio de Janeiro: Dois Pontos.

, (1999). O corpo na história. Rio de Janeiro: Fiocruz.

SAHLINS, Marshall, (1997). O "pessimismo sentimental" e a experiência etnográfica: por que a cultura não é um "objeto" em via de extinção (parte II). In : Mana - estudos de antropologia social. Rio de Janeiro: Contra Capa/PPGAS, v. 3, $\mathrm{n}^{\circ} 2$, p. $103-150$.

Recebido em março de 2003

Aprovado em março de 2003 